D.V. Tugay

\title{
THE PHASE REACTOR INDUCTANCE SELECTION TECHNIQUE FOR POWER ACTIVE FILTER
}

\begin{abstract}
Purpose. The goal is to develop technique of the phase inductance power reactors selection for parallel active filter based on the account both low-frequency and high-frequency components of the electromagnetic processes in a power circuit. Methodology. We have applied concepts of the electrical circuits theory, vector analysis, mathematical simulation in Matlab package. Results. We have developed a new technique of the phase reactors inductance selection for parallel power active filter. It allows us to obtain the smallest possible value of THD network current. Originality. We have increased accuracy of methods of the phase reactor inductance selection for power active filter. Practical value. The proposed technique can be used in the design and manufacture of the active power filter for real objects of energy supply. References 12, figures 11.

Key words: power active filter, coefficient of harmonic distortion, phase reactors inductance, frequency modulation, Matlabmodel of a three-phase energy supply system.
\end{abstract}

Цель. Целью статьи является разработка методики выбора индуктивности фазных реакторов параллельного силового активного фильтра, основанной на учете как низкочастотной так и высокочастотной составляющих электромагнитных процессов в силовой схеме. Методика. Для проведения исследований использовались положения теории электрических цепей, векторный анализ, математическое моделирование в пакете Матlab. Результаты. Разработана новая методика выбора индуктивности фазных реакторов параллельного силового активного фильтра, позволяющая получить минимально возможное значение коэффициента нелинейных искажений сетевого тока. Научная новизна. Повышена точность методов выбора индуктивности фазных реакторов силового активного фильтра. Практическое значение. Предложенная методика может использоваться при проектировании и изготовлении силовых активных фильтров для реальных объектов электроснабжения. Библ. 12, рис. 11.

Ключевые слова: силовой активный фильтр, коэффициент нелинейных искажений, индуктивность фазных реакторов, частота модуляции, Мatlab-модель трехфазной системы электроснабжения.

Introduction. Electromagnetic compatibility of electrical consumers with the supply of industrial network is one of the key factors considered in the selection and installation of electrical equipment designed for a large installed capacity. Stringent standards for power quality $[1,2]$ impose obligations both producers and customers of electrical equipment to take additional measures to comply with them, which affects the characteristics of the end product, its cost, and certification opportunities.

In the industrial and municipal power systems, electric transport the main segment of powerful consumers of electricity consumers up with non-linear characteristics [1-3]. Joint connection to industrial consumers such network causes an increase in emission level of higher harmonic components of the current network, the distortion of the supply voltage circulating in conductors linear reactive currents and, as a consequence, leads to increased energy losses in the power supply system [1-3]. Exclude or partially reduce the listed effects it is possible with the help of modern filter-devices, one of which is power active filter (PAF). PAF of parallel type the simplest diagram of power circuits is shown in Fig. 1 have the greatest popularity.

The power part of the PAF identical scheme of autonomous voltage inverter and executed on the power transistor, diode modules, forming a three-phase bridge shoulders. DC converter unit included a storage capacitor $C$, the voltage at which the automatic control system is supported by PAF above the line supply voltage amplitude

$$
U_{0}=k \cdot \sqrt{3} \cdot U_{s m}
$$

where $U_{s m}$ is the network phase voltage amplitude; $k=1.2-1.6$.

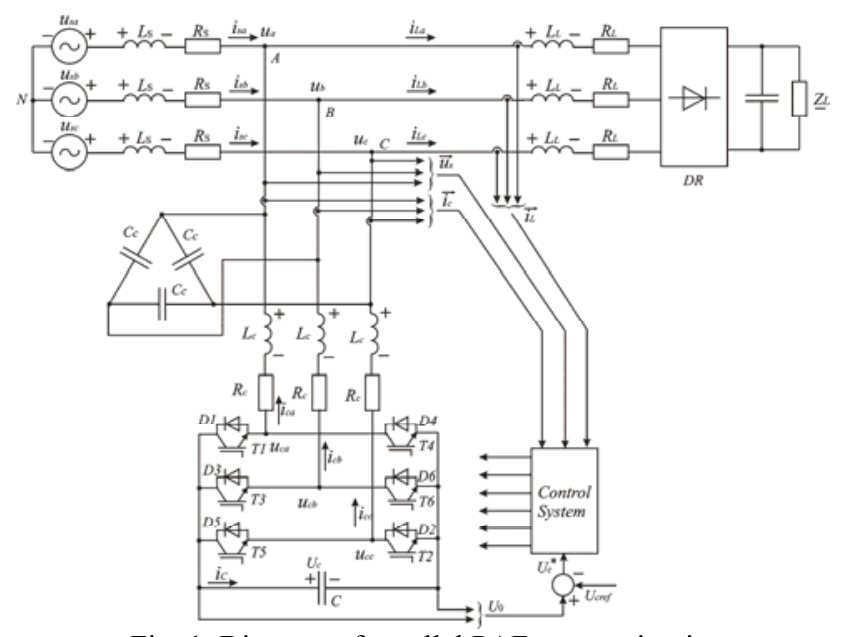

Fig. 1. Diagram of parallel PAF power circuits

In the input circuit of the PAF a three-phase reactor is connected with the parameters of the inductance $L_{c}$ and resistance $R_{c}$. To reduce high-frequency noise in the supply voltage at the input of the converter is connected in parallel with a three-phase filter of small capacity $C_{c}$.. Despite the simplicity of the power circuit and its power relative small element active filter is a complex dynamic device in which electromagnetic processes and parameters of circuit elements, depending on the mode and parameters of the load and the mains. Along with others, these factors complicate the calculation and selection of parameters of elements of power PAF scheme. The greatest difficulties arise when selecting the input inductance of $L_{c}$ reactors, simplified method of calculation which is mainly linked to the taking into account the current growth rate through the reactor 
winding commutations with transistor-diode keys, i.e. only the high-frequency component of the electromagnetic processes in a power scheme PAF [5-11]. As was shown in [12], this approach does not allow one to choose the parameters of the input reactor, so you need a new technique based on the specific operating conditions of the power compensator.

The goal of the paper is the development of a method of selecting values of phase power inductance of reactors of parallel power active filter based on the account as low-frequency and high-frequency components of the electromagnetic processes in the power circuit.

Features of the PAF operation. To analyze the characteristics of the PAF operation we will use a concrete example it is connected in parallel non-linear load, shown in Fig. 1. For the three-phase system with symmetrical sinusoidal voltage source $u_{s a}, u_{s b}, u_{s c}$ whose parameters $L_{s}$ and $R_{s}$ are uniquely defined, connected six-pulse uncontrolled rectifier $D R$ working on $R-L$ load. To restrict network rectifier ripple current last networked via an inductive reactor $L_{L}, R_{L}$ parameters. PAF is connected to terminals $\mathrm{ABC}$, where there are voltages $u_{a}, u_{b}, u_{c}$.

The principle of parallel PAF operation is based on generating compensation currents, which subtracts from the load current allows to obtain the desired shape of network currents. In this example, after connecting the PAF form of line current to be sinusoidal and instant network current should be in phase with the corresponding phase voltage.

Load current vector can be represented by a threecomponent vector, each component of which is a vector that stores information about the three current values of the respective phase currents

$$
\vec{i}_{L}=\left[\begin{array}{lll}
\vec{i}_{1 a} & \vec{i}_{1 r} & \vec{i}_{Z I}
\end{array}\right]^{T}
$$

where $\vec{i}_{1 a}$ is the vector of the fundamental harmonic active current three-phase system, which coincides with the direction of voltage vector $\vec{u}_{S}$ (see Fig. 1); $\vec{i}_{1 r}$ is the vector of the fundamental wave reactive power threephase system orthogonal to vector $\vec{i}_{1 a} ; \vec{i}_{\Sigma l}$ is the vector of total current harmonic load three-phase system.

PAF current vector can also be represented by a three-component vector

$$
\vec{i}_{C}=\left[\begin{array}{lll}
c_{1} \cdot \vec{i}_{1 r} & c_{2} \cdot \vec{i}_{\Sigma l} & \vec{i}_{\Sigma h}
\end{array}\right]^{T},
$$

where $\vec{i}_{\Sigma h}$ is the vector total current harmonics whose frequencies are multiples of side-frequency PWM; $c 1$ is the level of compensation of the primary harmonic of the reactive current $(0<c 1 \leq 1) ; c 2$ is the the level of compensation of the total load current of higher harmonics $(0<c 2 \leq 1)$. The first two components of the vector $\vec{i}_{C}$ describing the low-frequency component of the electromagnetic processes in PAF related to the characteristics of the load, and the third component - the high-frequency component, the appearance of which is associated with a feature of the compensator when switching of power semiconductor modules.

According to Fig. 1 and relations (2), (3) the line current vector at the working PAF may comprise four components

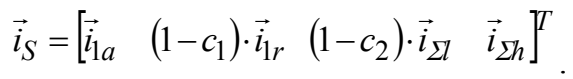

Quality compensation will depend on the values of the coefficients $c 1, c 2$ vector $\vec{i}_{\Sigma h}$. Under ideal conditions $c_{1} \approx 1, c_{2} \approx 1$, and $\left|\vec{i}_{\Sigma h}\right| \approx 0$. To achieve full compensation is virtually impossible in real installations. The quality of the PAF can be estimated value of the distortion factor $T H D_{i}$ line current. In accordance with (4) $T H D_{i}$ can be expressed as the sum of two components - a lowfrequency $\left(T H D_{i l}\right)$ and high-frequency $\left(T H D_{i h}\right)$

$$
T H D_{i}=T H D_{i l}+T H D_{i h}=\frac{\sqrt{\left(1-c_{2}\right)^{2} \cdot I_{\Sigma l}^{2}+I_{\Sigma h}^{2}}}{\sqrt{I_{1 a}^{2}+\left(1-c_{1}\right)^{2} \cdot I_{1 r}^{2}}},
$$

where $I_{\Sigma l}^{2}$ is the the sum of the squares of the rms values of higher harmonic components of the load current; $I_{\Sigma h}^{2}$ is the sum of the squares of the rms values of higher harmonic components whose frequencies are multiples of side-frequency PWM.

With an increase in the inductance of the input reactor PAF $T H D_{i l}$ low-frequency component is increased, and high-frequency component $T H D_{i h}$ decreases. Thus, there is an optimal value of inductance $L_{\text {opt }}$ corresponding to the minimum possible value $T H D_{i}$. To find the value $L_{\text {opt }}$ necessary to examine separately the electromagnetic processes in the PAF on the low and high frequency.

Consider the work of one phase of the PAF in the circuit according to Fig. 1. In the circuit in the open state are alternately transistor diode and one group of the same group opposite phase. For example, with a negative reference current compensator $i_{c a^{*}}$ in working condition will be the transistor $V T 1$ and diode VD4 circuit as shown in Fig. 2 . The term repeatability mains voltage in accordance with the nature of the non-linear load are three possibilities of joint work with the transistor VT1 transistor other two phases: $1-V T 1, V T 3, V T 2 ; 2-V T 1, V T 6, V T 5 ; 3-$ $V T 1, V T 6, V T 2$. Fig. 1 illustrates the first option. Depending on the duration of the conduction intervals of transistors employed and the current values of the phase voltages on the PAF input for the described embodiment are possible 8 states of the circuit shown in Fig. 3. At the time interval when the transistor $V T 1$, the energy stored in the capacitor $C$ is transmitted through the reactor $L_{c}$ in the network (Fig. 3,a,b) or stored in a capacitor through the reactors of the other two phases (Fig. 3,c). When transistor VT1 is closed in the open state is VD4 diode, and the energy stored in the reactor is transferred to the condenser, together with additional energy network (Fig. 3,e,g) is either returned to the network (Fig. 3,f). The time intervals in a conducting state when there are three groups of one semiconductor device (Fig. 3, $d$ and Fig. $3, h)$ the reactor is charged by the network. 


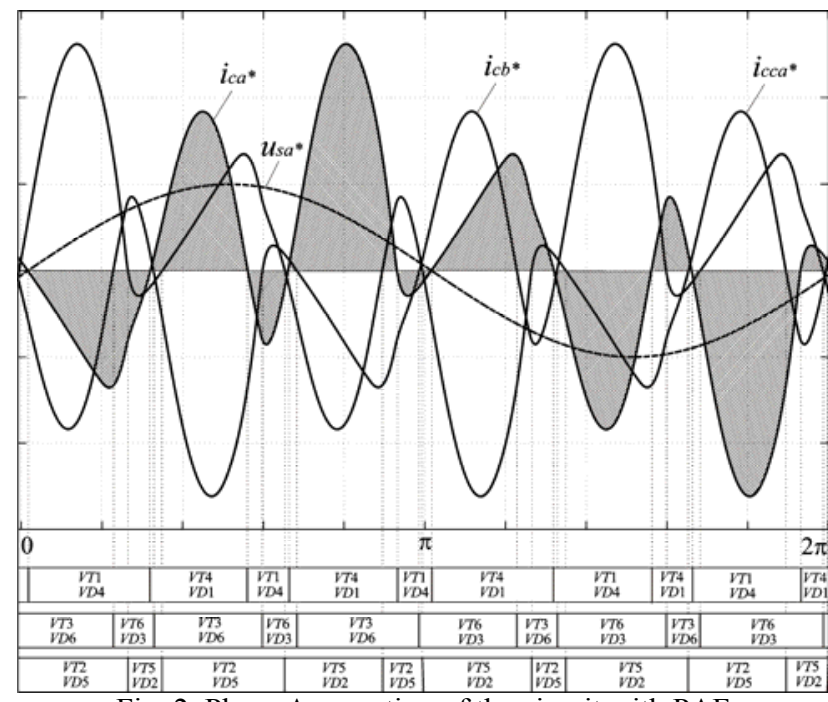

Fig. 2. Phase A operation of the circuit with PAF

Account of the low-frequency component of the electromagnetic processes in the selection phase inductance reactors. In accordance with Fig. 1, 2, and by (3) a low-frequency component of the PAF current can be represented as the sum of the reactive component of the first harmonic current, and harmonics of the order $6 n \pm 1$ due to the spectral composition of the input current six-pulse uncontrolled rectifier.

Let us evaluate the effectiveness of the PAF at the frequency of the mains voltage. Fig. 4 shows an equivalent circuit of one phase of the PAF for the fundamental harmonic voltage and current.

The first harmonic voltage, the current at the input rectifier bridge PAF is shown in the equivalent circuit source $u_{c a 1}$ and the load impedance phase - equivalent resistance $\underline{Z}_{L 1}$.

Fig. 5, $a$ and shows a vector diagram of the voltages and currents corresponding to the equivalent circuit of Fig. 4. The diagram shows that the instantaneous value of the first harmonic voltage at the input rectifier bridge $u_{c a 1}$ practically in phase with the instantaneous mains voltage $u_{s a}$. The amplitude of the fundamental harmonic voltage at the input rectifier bridge $\left(U_{m c a 1}\right)$ PAF will always be larger than the amplitude-phase mains voltage $\left(U_{\text {mcal }}\right)$ on the value of the voltage drop across the phase reactor $U_{m c L a 1}$

$$
U_{m c a l} \approx U_{m a}+U_{m c L a 1} \text {. }
$$

If we taking into account the orthogonal of vectors of current fundamental harmonic of the network $\vec{I}_{s a 1}$ and fundamental harmonic PAF $\vec{I}_{c a 1}$, the parameters of the source and the load to take the same, it is possible to prove the existence of the optimal value of inductance phase reactor $L_{o p t 1}$ ensuring the fulfillment of the above conditions.

In the vector diagram in Fig. $5, b$ shows that by increasing the inductance of the phase of the reactor there is a shift of the fundamental harmonic line current with respect to the supply voltage on the light angle $\varphi$ thereby deteriorating the quality of the PAF compensation.
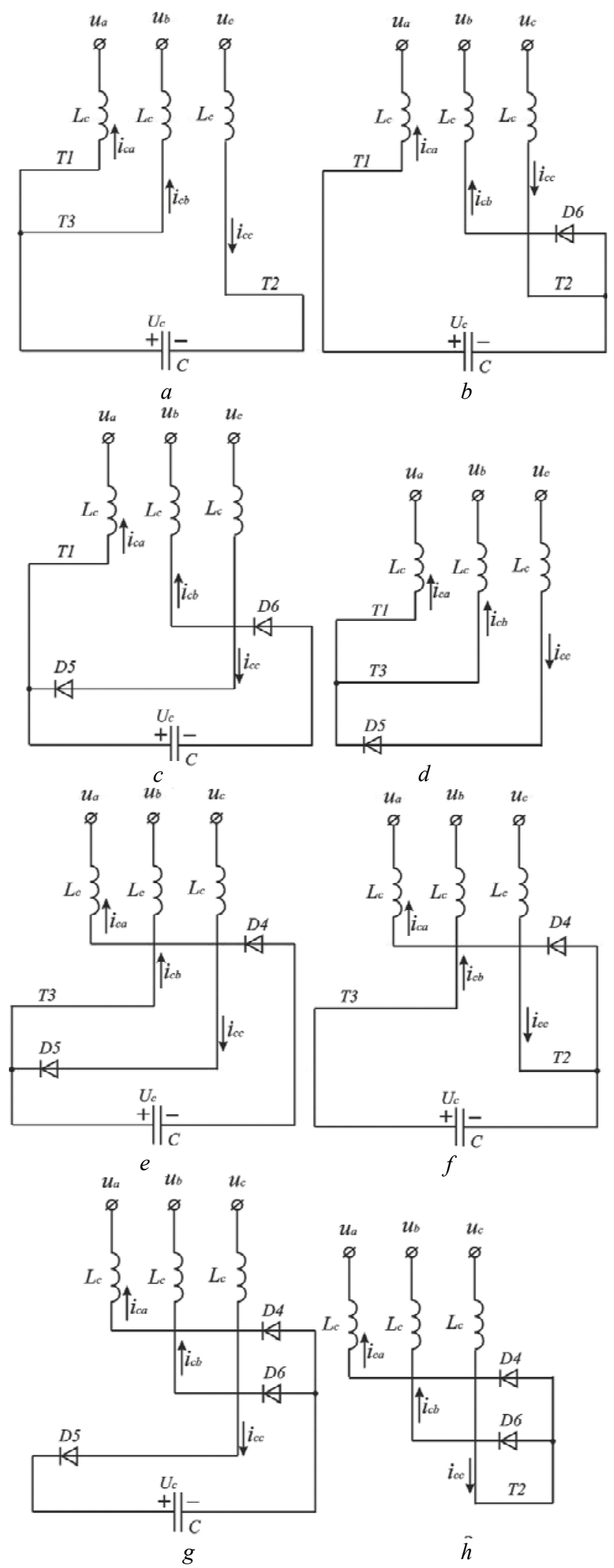

$\tilde{h}$

Fig. 3. Possible states of the PAF circuit at transistor $V T 1$ and diode $V D 4$ operation

Using a superposition method according to the equivalent circuit of Fig. 4 write ratio to calculate an integrated value of the fundamental harmonic load current. 


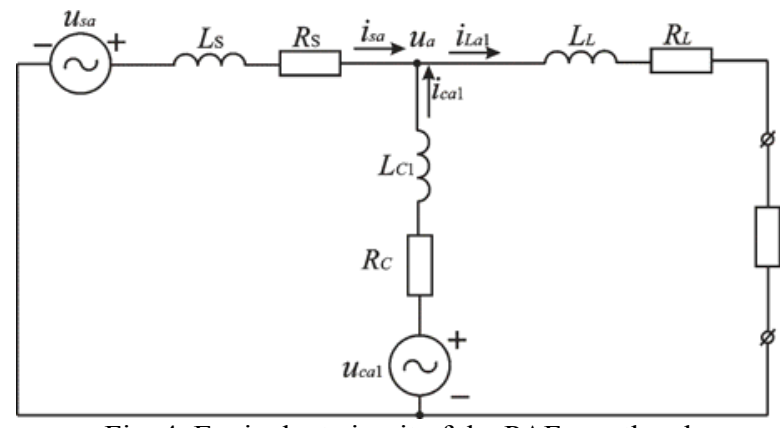

Fig. 4. Equivalent circuit of the PAF one the phase on the network voltage frequency

$$
\underline{I}_{L a 1}=U_{m a} \cdot \frac{\frac{\underline{Z}_{C}}{\underline{Z}_{11} \cdot\left(\underline{Z}_{L}+\underline{Z}_{C}\right)}-\frac{1}{\underline{Z}_{11}}+\frac{1}{\underline{Z}_{22}}}{1-\frac{\underline{Z}_{c}}{\underline{Z}_{22}}},
$$

where $\underline{Z}_{C}=R_{c}+j \omega L_{c} 1 ; \underline{Z}_{L}=R_{L}+j \omega L_{L}+\underline{Z}_{L} 1 ; \underline{Z} 11=$ $=\underline{Z}_{S}+\underline{Z}_{L} \cdot \underline{Z}_{C} /\left(\underline{Z}_{L}+\underline{Z}_{C}\right) ; \quad \underline{Z} 22=\underline{Z}_{C}+\underline{Z}_{L} \cdot \underline{Z}_{S} /\left(\underline{Z}_{L}+\underline{Z}_{S}\right) ; \underline{Z}_{S}=$ $=R_{s}+j \omega L_{s}$

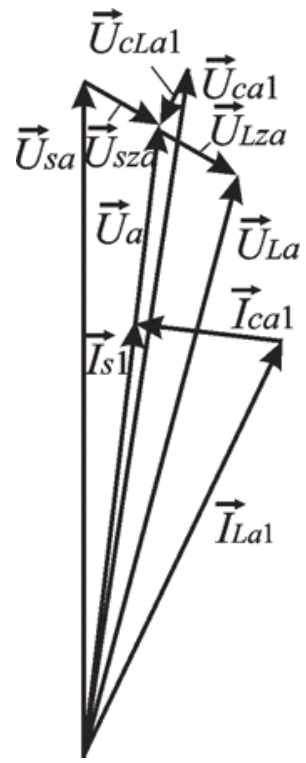

$a$

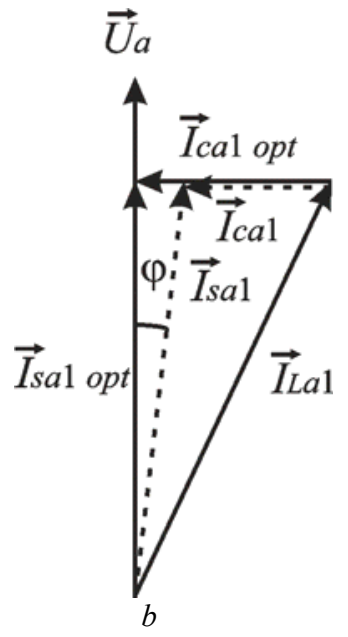

Fig. 5. Vector diagrams of voltages and currents of the equivalent circuit on the network voltage frequency

The real part of the complex values of the fundamental harmonic load current $\operatorname{Re}\left(\underline{I}_{L a 1}\right)$ corresponds to the optimum value of the fundamental harmonic current network $I_{s a 1}$ opt, and the imaginary part $\operatorname{Im}\left(\underline{I}_{L a 1}\right)$ - optimal value of the fundamental harmonic current PAF $I_{c a 1}$ opt .

Complex value of the fundamental harmonic voltage at the input of the rectifier bridge PAF

$$
\underline{U}_{c a 1}=U_{a}+j \cdot \operatorname{Im}\left(\underline{I}_{L a 1}\right) \cdot \underline{Z}_{C} .
$$

From the equivalent circuit (Fig. 4) we express the imaginary part of the complex values of the fundamental harmonic current PAF

$$
\underline{I}_{c a 1}=\operatorname{Im}\left(\frac{\underline{U}_{c a 1}}{\underline{Z}_{22}}-\frac{U_{a} \cdot \underline{Z}_{L}}{\underline{Z}_{11} \cdot\left(\underline{Z}_{L}+\underline{Z}_{C}\right)}\right) .
$$

Fig. $6, a$ and shows the dependence of the fundamental harmonic current PAF on the relative values (in the total inductance of the load shares $L_{L} \Sigma=$ $\left.=L_{L}+\operatorname{Im}\left(\underline{Z}_{L} 1\right) / \omega\right)$ phase inductance $\mathrm{PAF}$ reactor at different values of relative total inductance of the load and a fixed value of the network relative inductance $L_{S} / L_{L} \Sigma=0.065$. Dependencies are constructed with the following parameters of the equivalent circuit elements: $U_{m a}=311.13 \mathrm{~V}, R_{c}=R_{L}=0.002 \Omega, R_{s}=0.00036 \Omega, L_{L}=$ $=75 \mu \mathrm{H}, \underline{Z}_{L} 1=0.438+j 0.358 \Omega$.
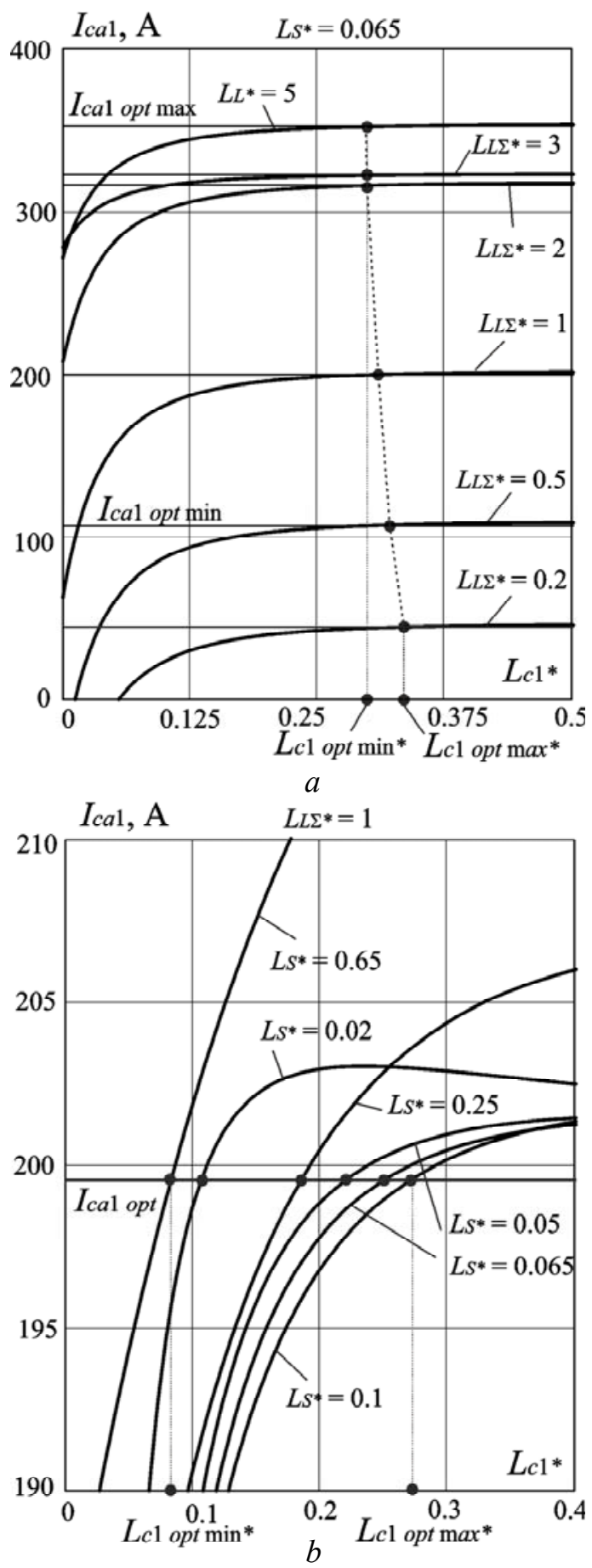

Fig. 6. Dependencies $I_{c a 1}=f\left(L_{c 1^{*}}\right)$

Fig. $6, b$ shows the dependence of the fundamental harmonic current SAF on the relative values of the inductance of the phase reactors SAF for different values of the network inductance and fixed value relative total inductance load $L_{L \Sigma^{*}}=1$. 
At the intersection built in Fig. 6 curves with curves corresponding optimal value of current fundamental harmonic PAF $I_{c a 1}$ opt are point abscissa are equal to the optimum values of the phase inductance reactors $L_{\text {opt } 1}$.

From a comparison of Fig. 6,a and Fig. 6,b it can be concluded that the optimum value of the phase inductance reactors PAF largely depends on the inductance of the network than the load inductance. If the total inductance of the load changes from $0.2 L_{L \Sigma^{*}}$ to $3 L_{L \Sigma^{*}}$ optimum value of the phase inductance reactors PAF decreased from $0.275 L_{L \Sigma^{*}}$ to $0.261 L_{L \Sigma^{*}}$. If you change the network inductance of $0.02 L_{L \Sigma^{*}}$ to $0.65 L_{L \Sigma^{*}}$ range of the optimum load inductance is much wider from $0.083 L_{L \Sigma^{*}}$ to $0.273 L_{L \Sigma^{*}}$. Moreover, by increasing the inductance of first optimum network inductance increases, and after a certain $L_{s^{*}}$ value decreases.

From the vector diagram in Fig. 6 we obtain the ratio to calculate the angle of the shift of the fundamental harmonic phase current with respect to the appropriate voltage

$$
\varphi=\arctan \left(\frac{\operatorname{Im}\left(I_{L a 1}\right)-\operatorname{Im}\left(I_{c a 1}\right)}{\operatorname{Re}\left(I_{L a 1}\right)}\right) .
$$

Fig. 7 shows the dependence of the angle $\varphi$ of the relative phase inductance reactors $L_{c 1}$ for various values of a combination of the relative inductance of the network and relative total inductance of the load.

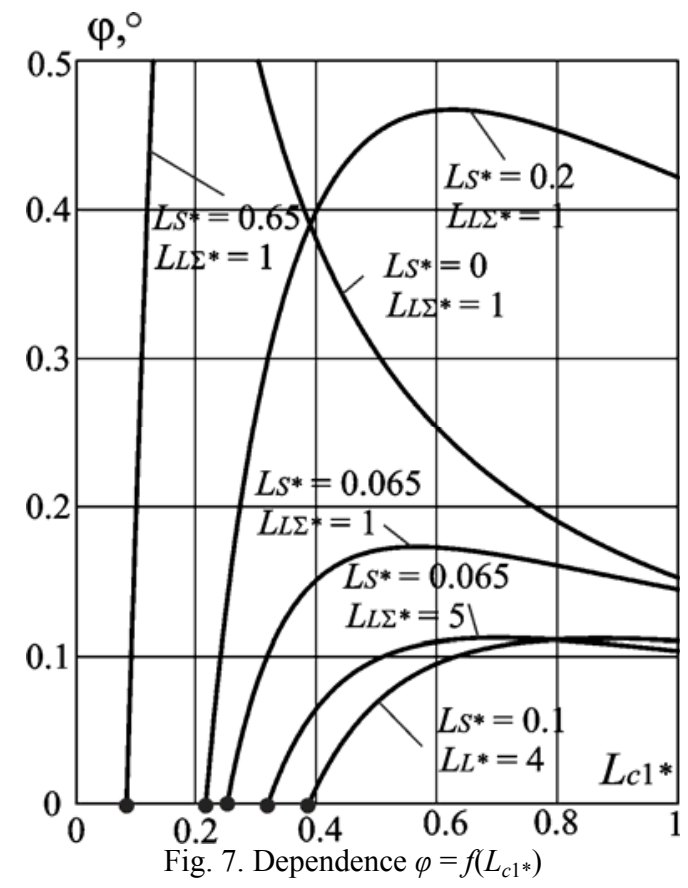

The optimal values of the inductance of the phase reactors correspond to points of intersection of plotting with the horizontal axis $(\varphi=0)$. If the inductance of the network is unknown or tends to zero, the point of intersection of the graph with the $x$-axis will be absent (see. Fig. 7 at $L_{s^{*}}=0, L_{L \Sigma^{*}}=1$ ). In such a case it is necessary to limit the range of variation of inductance values PAF phase reactors, in which the angle $\varphi$ will not vary by more than $1^{\circ}$. In this example, the corner $\varphi=1^{\circ}$ value corresponds to the inductance of the relative phase reactors $L_{c 1 *}=0.15$.
Account of the high-frequency component of the electromagnetic processes in the selection phase inductance reactors. We consider the work of one PAF when alternately switched transistor VT1 and diode VD4. According to Fig. 2 and Fig. 3 in the first working interval $V T 1$ and VD4 alternate conductivity four options PAF circuit state (Fig. 3,a, Fig. 3,d, Fig. 3,f, Fig. 3,h). Fig. 8 shows SAF current shape in the first valve $V T 1$ and $V D 4$ working conduction interval corresponding to one period of modulation $T_{\text {mod }}$.

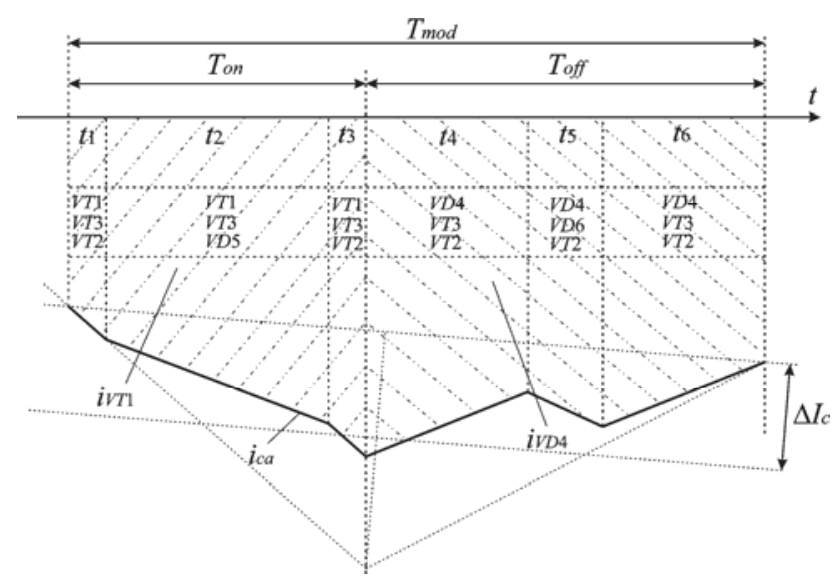

Fig. 8. Current shape of the PAF in the conduction interval VT1 and VD4 corresponding to one period of modulation $T_{\text {mod }}$

The short time intervals $\mathrm{t} 1$ and $\mathrm{t} 3$ (see. Fig. 3,a) when in the open condition of the transistors VT1,VT3, $V T 2$ the energy stored in the capacitor is transmitted into the network. The time intervals $t_{2}$ and $t_{5}$ when in a conducting state at the same time the valves are three phases of one group (see. Fig. 3, $d$ and Fig. 3,h) $L_{c}$ reactor stores energy from the network. At time intervals $t_{4}$ and $t_{6}$ along with transistors VT3, VT2 involved diode VD4 (Fig. 3, f) the energy stored in the reactor is returned to the network.

From Fig. 8 it can be seen that in the period of modulation $T_{\text {mod }}$ greatest slope of the curve corresponds to the current instant network time intervals $t_{1}$ and $t_{3}$, when open transistors VT1,VT3, VT2. For Fig. 3, $a$ the following relation is correct

$$
\frac{d i_{c a}}{d t} L_{c}=u_{s a}+\frac{U_{C}}{3}
$$

and for Fig. 3,d

$$
\frac{d i_{c a}}{d t} L_{c}=u_{s a}
$$

Using auxiliary constructions shown in Fig. 8, it is easily to determine the maximum angle of PAF current [6]

$$
\frac{\Delta i_{c a}}{\Delta t}=\frac{2 \cdot \Delta I_{c}}{T_{\text {mod }} / 2}=4 \cdot \Delta I_{c} \cdot f_{\text {mod }},
$$

where $\Delta I_{c}$ is the maximum deviation of the instantaneous current of the current PAF set, $f_{\text {mod }}$ is the frequency pulse width modulation. Let us consider the case when $f_{\text {mod }}=$ const.

Substituting the relation (1), (13) in (11) we obtain the equation for determining the minimum inductance phase reactor PAF 


$$
L_{c \min 2}=\frac{U_{m} \cdot\left(1-\frac{k}{\sqrt{3}}\right)}{4 \cdot f_{\bmod } \cdot \Delta I_{c^{*}} \cdot \operatorname{Re}\left(I_{L a 1}\right)},
$$

where

$$
\Delta I_{c^{*}}=\frac{\Delta I_{c}}{I_{s a 1}}=\frac{\Delta I_{c}}{\operatorname{Re}\left(\underline{I}_{L a 1}\right)} .
$$

With a high degree of accuracy (14) can be replaced by a simplified relationship

$$
L_{c \min 2}=\frac{R_{L \Sigma} \cdot\left(1-\frac{k}{\sqrt{3}}\right)}{4 \cdot f_{\bmod } \cdot \Delta I_{c^{*}}} .
$$

where $R_{L} \Sigma=R_{L}+\operatorname{Re}\left(\underline{Z}_{L} 1\right)$ is the total resistance of the load phase.

From Fig. 3, $d$ in a similar manner to obtain the ratio of the maximum value of PAF inductance phase reactor, substituting (1), (13) in (12) and bearing in mind that the maximum voltage at the time of switching transistor reaches half the phase voltage amplitude $u_{s a} \approx 0.5 U_{m}$ (see Fig. 2)

$$
L_{c \max 2}=\frac{R_{L \Sigma}}{8 \cdot f_{\bmod } \cdot \Delta I_{c^{*}}} .
$$

The relative value of the average inductance of the reactor phase

$$
L_{c 2^{*}}=\frac{L_{c \min 2}+L_{c \max 2}}{2 \cdot L_{L \Sigma}}=\frac{1.5-\frac{k}{\sqrt{3}}}{8 \cdot f_{\bmod } \cdot \Delta I_{c^{*}} \cdot \tau_{L}},
$$

where $\tau_{L}=L_{L} \Sigma / R_{L} \Sigma$ is the time constant of the load phase.

Fig. 9 shows the dependence of the relative values of the inductance of the phase reactors by PAF parameter $\Delta I_{c^{*}}$ for various values of the modulation frequency $f_{\text {mod }}$ for these parameters earlier scheme.

Method of choosing PAF inductance. On the basis of the material presented above describe the steps to select inductance phase reactors PAF. Consider a specific example of the application of the scheme PAF with the previous settings of its elements.

1. We determine total load inductance $\left.L_{L \Sigma}=L_{L}+\operatorname{Im}\left(\underline{Z}_{L 1}\right) / \omega\right)$. In the example $L_{L \Sigma}=0.433 \mathrm{mH}$.

2. From the known parameters of the scheme, using the relation (7) expect to complete the value of the first harmonic of the load current. In the example $I_{L a 1}=$ $=645.4-j 199.5 \mathrm{~A}$.

3. Using (8) we obtain the relation for the calculation of the first harmonic current SAF in the form (9).

4. By (10) we build dependence $\varphi=f\left(L_{c 1^{*}}\right)$ (see Fig. 7).

5. At the intersection of the curve $\varphi=f\left(L_{c 1^{*}}\right)$ with the $x$ axis determines the point coordinate which corresponds to the optimum value of the relative phase of the reactor inductance PAF. In the example $L_{c 1 \text { opt* }}=0.249\left(L_{c 1 \mathrm{opt}}=\right.$ $=0.108 \mathrm{mH}$ ).

6 . The obtained value of inductance is substituted in equation (18) and determines the relative value of the maximum deviation of the instantaneous current of the given current PAF $\Delta I_{c^{*}}$. In the example $\Delta I_{c^{*}}=0.059$.
7. If the value $\Delta I_{c^{*}}$ more than $5 \%$ from the first harmonic amplitude of the current network, we make adjustments of parameters. In the example, you can slightly increase the modulation frequency to the value $f_{\text {mod }}=7045 \mathrm{~Hz}$, and $\Delta I_{c^{*}}=0.05$.

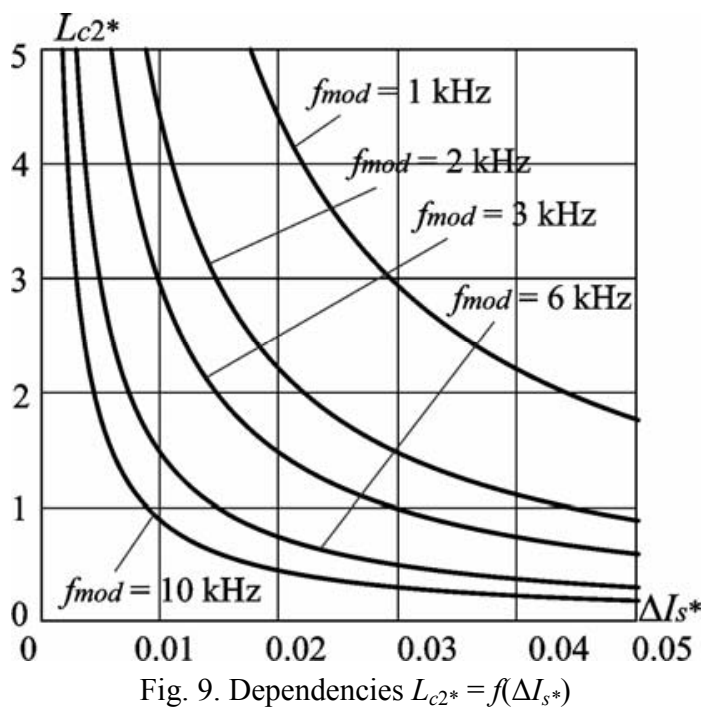

Experimental verification of the theoretical results. To test the proposed methodology has been developed Matlab-model of a three-phase power supply system with a non-linear load and parallel active filter shown in Fig. 10.

Matlab-model consists of 5 groups of blocks:

1. Power circuit (Us - three-phase voltage source with definable parameters; DR - three-phase uncontrolled rectifier; Load - rectifier load; PAF - inverter bridge of PAF; $\mathrm{C}$ - DC link capacitor of PAF; Rc - charging resistor; LL - load current smoothing reactor; Lpaf1, Lpaf2 - PAF phase reactor divided into two sections; Cpaf - PAF input capacitor filter; SA_PAF, SA_C - three-phase contactors of PAF and capacitor filter, respectively).

2. Currents and voltages sensors (blocks Is, IL, Ipaf, U, UL, Upaf, UC).

3. Control system (Control System - PAF control system; Gate_Paf, Gate_G, Gate_C, Gate_R - power circuit control blocks).

4. Measuring subsystem (Measurements - subsystem for calculating total harmonic distortion and operating currents).

5. Virtual instrumentation (Multimeters - multimeters; Us_Is, Upaf_Ipaf, Uc-oscilloscopes).

For computer simulation the same parameters elements of the power circuit, as for the calculation of the phase inductance reactors PAF were chosen. In the experiment, the input capacitor filter PAF has been disconnected. 


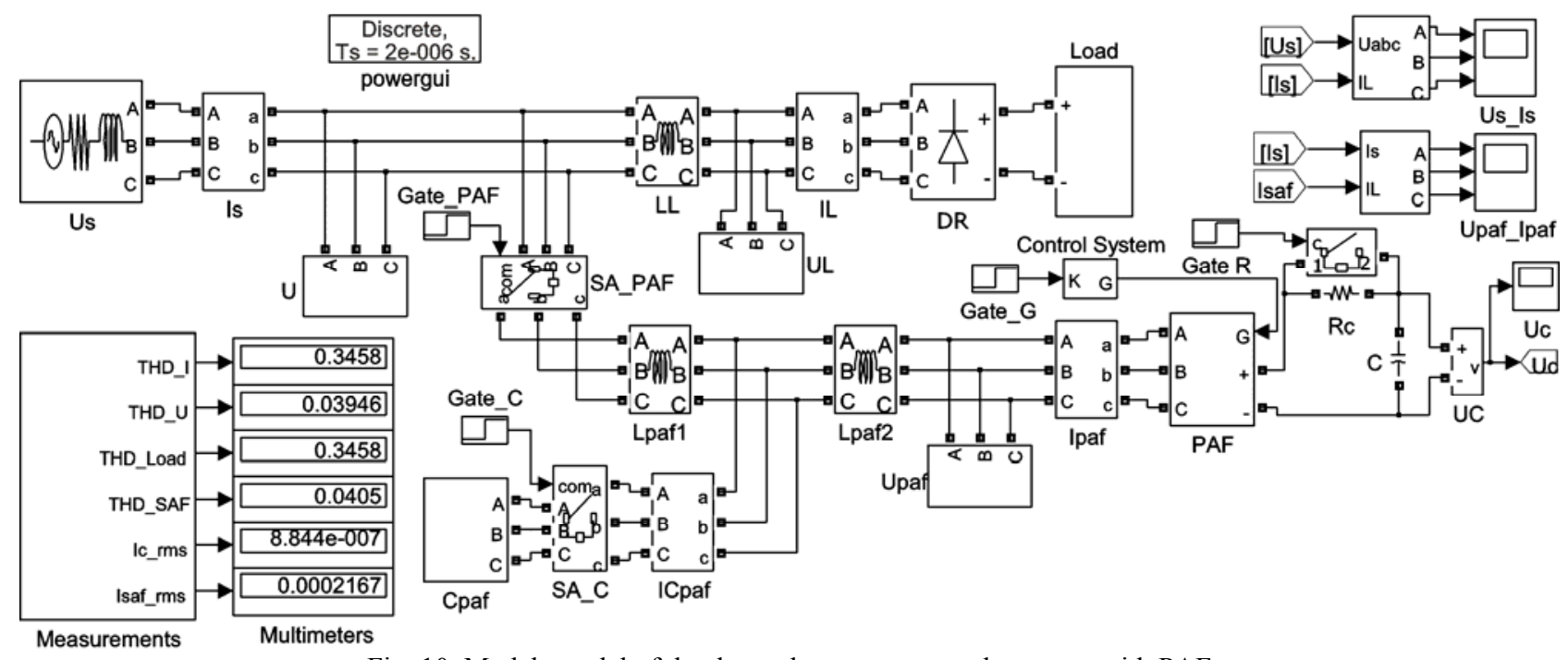

Fig. 10. Matlab-model of the three-phase power supply system with PAF

Fig. 11 shows the current waveform of phase A for three values of the relative phase inductance reactors PAF: $L_{c^{*}}=L_{\text {opt }}=0.249$ - Fig. 11, $a ; L_{c^{*}}=0.577$ - Fig. $11, b ; L_{c^{*}}=0.093$ - Fig. $11, c$. In the figures also indicate the values of the line current THD. The experiment confirmed that the minimum possible value of the line current THD for given circuit parameters corresponding to the selected value of the inductance of the phase reactors PAF. Further studies have shown that when the input PAF C-filter (see Fig. 1) THD line current can be reduced by 1 $\%$ (i.e., up to $5 \%$ ).
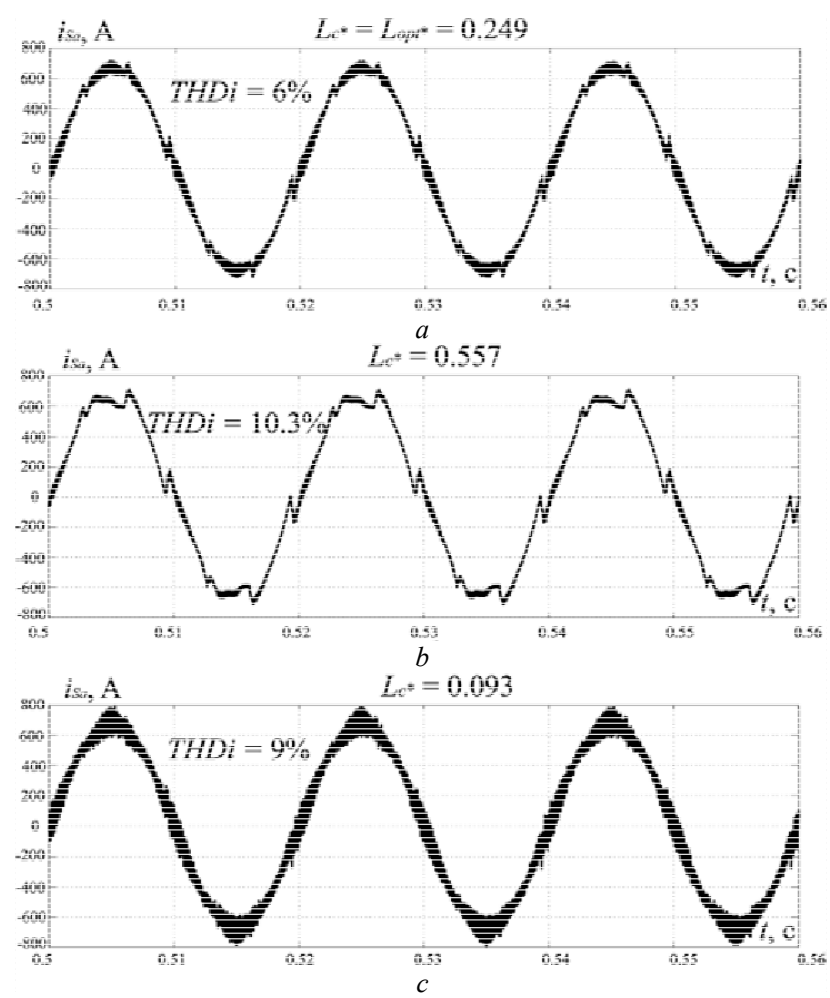

Fig. 11. Waveforms of the network current of the phase A at three values of the PAF phase reactors inductance

Conclusions.

1. The correct choice of inductance of PAF should be based on the account of the two components of the electromagnetic processes in the power circuit - the low- frequency one related with compensation of reactive power and harmonic load current and high frequency one associated with the processes of «pumping» of energy in phase reactor of PAF.

2. It is proved that the optimal value of inductance of phase reactors corresponds to the smallest possible THD of the line current.

3. The method of selecting inductance of PAF phase reactors taking into account the parameters of elements of the supply network and the load, i.e., the specific operating conditions of the PAF in the power supply system is developed. The proposed method can be used in the design and manufacture of PAF for installation on concrete objects.

\section{REFERENCES}

1. EN 50160:2010 Voltage characteristics of electricity supplied by public distribution networks.

2. IEC 61000-3-4 Electromagnetic compatibility (EMC) - Part 3-4: Limits - Limitation of emission of harmonic currents in low-voltage power supply systems for equipment with rated current greater than $16 \mathrm{~A}$.

3. Hafner J., Aredes M., Heumann K. A shunt active power filter applied to high voltage distribution lines. IEEE Transactions on Power Delivery, 1997, vol.12, no.1, pp. 266-272. doi: 10.1109/61.568249.

4. Bhattacharya S., Frank T., Divan D., Banerjee B. Parallel active filter system implementation and design issues for utility interface of adjustable speed drive systems. IAS '96. Conference Record of the 1996 IEEE Industry Applications Conference Thirty-First IAS Annual Meeting, 1996, pp. 1032-1039. doi: 10.1109/ias.1996.560208.

5. Moran L.A., Dixon J.W., Wallace R.R. A three-phase active power filter operating with fixed switching frequency for reactive power and current harmonic compensation. IEEE Transactions on Industrial Electronics, 1995, vol.42, no.4, pp. 402-408. doi: $10.1109 / 41.402480$.

6. Aburto V., Schneider M., Moran L., Dixon J. An active power filter implemented with a three-level NPC voltage-source inverter. PESC97. Record 28th Annual IEEE Power Electronics Specialists Conference. Formerly Power Conditioning Specialists Conference 1970-71. Power Processing and Electronic Specialists Conference 1972, 1997, vol.2, pp. 1121-1126. doi: 10.1109/PESC.1997.616889.

7. Al-Zamil A.M., Torrey D.A. A passive series, active shunt filter for high power applications. IEEE Transactions on Power 
Electronics, 2001, vol.16, no.1, pp. 101-109. doi: 10.1109/63.903994.

8. Asiminoaei L., Eddy A., Prasad N.E., Blaabjerg F. Shunt active-power-filter topology based on parallel interleaved inverters. IEEE Transactions on Industrial Electronics, 2008, vol.55, no.3, pp. 1175-1189. doi: 10.1109/TIE.2007.907671.

9. Bento A.A.M., da Silva E.R.C., Praça P.P. Integrated onecycle control for three-leg universal active power filter. 2008 IEEE Power Electronics Specialists Conference, June, 2008, pp. 3974-3980. doi: 10.1109/PESC.2008.4592575.

10. Ivanets S.A., Gusev O.O., Chub A.I. Methods of elements selection for parallel filter-compensating converter. Journal of Chernihiv State Technological University. Series: Engineering, 2009, no.40, pp. 223-232. (Ukr).

11. Stepenko S.A., Gusev O.O., Ivanets S.A., Veligorskyi O.A. Comparative analysis of methods for control of filtercompensating devices. Bulletin of the Kyiv National University of Technologies and Design, 2012, no.1, pp. 82-88. (Ukr).

How to cite this article:

Tugay D.V. The phase reactor inductance selection technique for power active filter. Electrical engineering \& electromechanics, 2016, no.6, pp. 31-38. doi: 10.20998/2074-272X.2016.6.06.
12. Zhemerov G.G., Krylov D.S., Tugay D.V. Verification of the calculation elements and high-quality performance of the power supply system with a parallel power active filter. Bulletin of $N T U$ «KhPI», 2015, no.12, pp. 394-397. (Rus).

Received 27.10.2016

D.V. Tugay, Candidate of Technical Science, Associate Professor,

O.M. Beketov National University of Urban Economy in Kharkiv,

12, Revolution Str., Kharkiv, 61002, Ukraine.

phone+38057 7073111, e-mail: tugaydv@yandex.ua 